\title{
Comparison of unintentional fatal occupational injuries in the Republic of Korea and the United States
}

\author{
Y-S Ahn, J F Bena, A J Bailer
}

Injury Prevention 2004;10:199-205. doi: 10.1136/ip.2003.004895

See end of article for authors' affiliations

..........

Correspondence to: Professor A J Bailer, Department of

Mathematics and Statistics, Miami University, Oxford, $\mathrm{OH}$ 45056, USA;

baileraj@muohio.edu

\begin{abstract}
Objectives: To compare the profile of unintentional fatal occupational injuries in the Republic of Korea and the United States to help establish prevention strategies for Korea and to understand country specific differences in fatality risks in different industries.

Methods: Occupational fatal injury data from 1998-2001 were collected from Korea's Occupational Safety and Health Agency's Survey of Causes of Occupational Injuries (identified by the Korea Labor Welfare Corporation) and from the United States Census of Fatal Occupational Injuries. Employment estimates were obtained in both countries. Industry coding and external cause of death coding were standardized. Descriptive analyses of injury rates and Poisson regression models to examine time trends were conducted.

Results: Korea exhibited a significantly higher fatal injury rate, at least two times higher than the United States, after accounting for different employment patterns. The ordering of industries with respect to risk is the same in the two countries, with mining, agriculture/forestry/fishing, and construction being the most dangerous. Fatal injury rates are decreasing in these two countries, although at a faster rate in Korea.

Conclusions: Understanding industrial practices within different countries is critical for fully understanding country specific occupational injury statistics. However, differences in surveillance systems and employment estimation methods serve as caveats to any transnational comparison, and need to be harmonized to the fullest extent possible.
\end{abstract}

$\mathrm{O}$ ccupational injuries continue to represent a serious public health concern for workers throughout the world. It has been estimated that the global annual occupational fatal injury rates are 14 deaths per 100000 workers. ${ }^{1}$ The rates are much lower in industrialized countries than in less industrialized countries. Countries in established market economies averaged five deaths per 100000 workers, countries in former socialist economies of Europe, India, and China all reported 11 deaths per 100000 workers, while other Asian countries and islands had an average of 23 per 100000 workers. In Korea, the rate was extremely low during the 1960s in the early stages of economic growth. ${ }^{2}$ An increase from 33 deaths in 1964 to 639 deaths (82.0 deaths per 100000 workers) in 1970 to 1006 deaths (54.8 deaths per 100000 workers) in 1975 was observed in Korea. ${ }^{2}$ This was at a time when full scale economic development began and industrial and technological innovations brought rapid changes to the working environments. Changes in safety awareness at the workplace and the government's steady injury prevention activities may have helped lead to a gradual decline in fatalities after $1980 .^{3}$ A decrease in fatalities from 33.9 deaths per 100000 workers (1273 deaths) in 1980 to 16.6 deaths per 100000 workers (1533 deaths) in 2000 was observed in Korea. ${ }^{2}$ Even with this decline, the rate is still higher than that of developed countries such as the United States. What might explain these differences? They might simply reflect differences in workplace practices among countries even within similar industries. These differences also might be explained if different countries' surveillance systems have differential coverage for these injuries. Addressing these questions may help establish the plan for decreasing the occupational injury rate of Korea to that of developed countries. This study was conducted to compare the characteristics of occupational fatal injuries in South Korea and the United States. This may be one of the first direct comparisons of a developing economy and an established economy with respect to injuries. Methods were developed that allowed for the creation of similar industry and injury definitions to be used for data from both countries. Fatality rates were generated overall and by industry division. Identifying the subgroups of the population where these rates differ is helpful for understanding the cause of the high rates in Korea. Particular industries or injury causes of notable concern in Korea and the United States can be highlighted by this analysis. Finally, this analysis offers another illustration of the challenge of comparing occupational health outcomes across countries, and the need for coordinated, harmonized systems to facilitate such comparisons.

\section{METHODS \\ Data}

Occupational injury fatalities in the United States for the years 1998 through 2001 were obtained from the Bureau of Labor Statistics' Census of Fatal Occupational Injuries (CFOI), a multiple source surveillance system maintained by the Bureau of Labor Statistics. Demographic information of the deceased person, and information about the employer and nature of the injury is reported in the CFOI system. ${ }^{4}$ Deaths with missing industry values were excluded from rate calculations, but included in cause of death analyses. Deaths in the public sector (including all federal, state, and local government employees) were eliminated to maintain compatibility with the Korean dataset. While intentional injuries are a common cause of occupational fatalities in the United States, these are rare in Korea, and are not included in the Korean data. Intentional injuries accounted for

Abbreviations: CFOI, Census of Fatal Occupational Injuries; ICE, International Collaborative Effort; KLWC, Korea Labor Welfare Corporation; KOSHA, Korea Occupational Safety and Health Agency; OIICS, Occupational Injury and IIIness Classification System 
approximately $15 \%$ of occupational fatalities in the United States from 1998 through $2001 .^{5}$

Fatal injury rates were constructed using the number of workers employed in a particular year as the denominator. In the United States these were based on tabulations in the Current Population Survey, ${ }^{6}$ a monthly sample of workers aggregated to yield annual estimates of employment.

Korean fatality data for the same years were provided from Korea Occupational Safety and Health Agency (KOSHA) Survey of Causes of Occupational Injuries, primarily collected from Korea Labor Welfare Corporation (KLWC), which is Korea's only insurance company for workers' compensation but which excludes governmental officials, professional soldiers, and educational staff. If an injury claimed by a worker was classified as an occupational injury by KLWC, information was entered into an electronic database. The inclusion criterion for entry in the KLWC data set is all work related injuries regardless of the location where the injury occurred. It also includes all employed workers regardless of the characteristics of workers (age, sex, nationality) and companies (size, industry type). (KOSHA is also able to access the KLWC's electronic file (raw data) for compensated cases through the electronic network between KLWC and KOSHA. KOSHA has specialists verify the cause of injury in detail for all fatalities through a survey of compensated cases using a questionnaire administered by mail and telephone.) Each case has information about sex, age, cause of injuries, type of industries, and size of companies. Data from 19982001, extracted from the KLWC data and reviewed by KOSHA, are used in this analysis.

Denominators for computing fatality rates from the Korean data were the total number of workers employed by companies contracted with the KLWC. Employment data include number of workers by type of industries and size of companies in each calendar year.

Appendix table 1 provides a comparison of the occupational injury surveillance systems between Korea and United States. Part of the challenge of comparing data across countries becomes apparent from a review of this table. Different sources of case determination (compensated injury claims in Korea $v$ multiple source identification in the United States) are one confounder of any cross country comparison. Coding of industry and cause of death are two additional areas where differences need to be reconciled before any comparison.

\section{Data aggregation}

To allow for direct comparison between the countries both the industry and injury cause classification systems in the two countries were matched. Deaths in the United States were classified by industry divisions-codes from the Standard Industrial Classification system ${ }^{7}$ classified into 10 large categories. Korean fatalities were classified using the Korean Standard Industrial Classification System. ${ }^{8}$ To facilitate comparisons between industries, six industry groups were formed and are presented in appendix table 2 along with the industry division codes from each country that comprise the groups. Fatal injuries in the United States were classified using the Occupational Injury and Illness Classification System (OIICS). ${ }^{9}$ Deaths in Korea were classified using the Causes of Occupational Injury and Disease Classification System, ${ }^{10}$ a system that closely resembles the OIICS and has 19 injury categories and six disease categories. Fatalities were classified into 10 groups that cover causes from each of the systems. These fatality groups are presented in appendix table 3 along with the United States and Republic of Korea injury codes that make up each group.

\section{Data summaries and statistical methods}

Annual fatal injury rates were estimated using the number of occupational deaths for a subgroup in a year divided by the number of workers in that subgroup in the same year. This provides an estimate of risk per worker-year in that subgroup, reported on a per 100000 worker-years basis.

Poisson regression was used to assess time trends. Poisson regression models are generalized linear models with a log link and a Poisson response distribution. ${ }^{11}$ To measure time trends, log fatality rates were represented as a function of calendar year. The basic model used had the form: log (rate $)=\beta_{0}+\beta_{1}$ * (year -1998$)$ where $\beta_{0}$ was the log fatality rate in 1998, the first year of the study, and $\beta_{1}$ the annual time trend parameter. In the Poisson regression model, the number of fatal injuries is the response, while the $(\log )$ number employed served as an offset in the model. These models were fit using the SAS GENMOD procedure. ${ }^{12}$

Values of the estimated parameters are reported as:

$$
100000 * e^{\hat{\beta}_{0}} \text { and } 100 *\left(e^{\hat{\beta}_{1}}-1\right)
$$

which are the estimated annual fatality rate per 100000 worker-years in the first year of the study (1998) and the estimated annual percentage change in fatal injury rates, respectively. These models were fit to data from each country as a whole and then stratified by other variables of interest, such as industry groups within each country.

To evaluate whether differences in fatal injury rates were due to differences in employment structure between countries, we calculated a directly adjusted United States fatal

Table 1 Comparison of Korea and United States (US) percentage distributions of unintentional fatal injuries and employment, overall and by industry

\begin{tabular}{|c|c|c|c|c|}
\hline Industry & Country & No $(\%)$ deaths & No (\%) employed* & Rate per 100000 \\
\hline \multirow{4}{*}{$\begin{array}{l}\text { Agriculture, } \\
\text { forestry, fishing } \\
\text { Mining }\end{array}$} & Korea & $109(2.3)$ & $0.3(0.9)$ & 33.0 \\
\hline & US & $2893(15.8)$ & $13.7(2.7)$ & 21.1 \\
\hline & Korea & $135(2.8)$ & $0.1(0.2)$ & 161.0 \\
\hline & US & 586 (3.2) & $2.3(0.4)$ & 25.8 \\
\hline \multirow[t]{2}{*}{ Construction } & Korea & 1971 (40.8) & $8.3(23.6)$ & 23.8 \\
\hline & US & 4600 (25.2) & $36.6(7.1)$ & 12.6 \\
\hline \multirow[t]{2}{*}{ Manufacturing } & Korea & 1408 (29.2) & $10.5(29.9)$ & 13.4 \\
\hline & US & 2473 (13.5) & $79.8(15.6)$ & 3.1 \\
\hline \multirow{4}{*}{$\begin{array}{l}\text { Transport, public } \\
\text { utility } \\
\text { Other industries }\end{array}$} & Korea & 492 (10.2) & $2.7(7.8)$ & 18.1 \\
\hline & US & 3452 (18.9) & $38.4(7.5)$ & 9.0 \\
\hline & Korea & 715 (14.8) & $13.2(37.5)$ & 5.4 \\
\hline & US & 4257 (23.3) & $341.7(66.7)$ & 1.2 \\
\hline \multirow[t]{2}{*}{ Total } & Korea & $4830(100)$ & $35.1(100)$ & 13.8 \\
\hline & US & $18261(100)$ & $512.5(100)$ & 3.6 \\
\hline
\end{tabular}


injury rate using the industry specific number of Korean workers as the standard population. We also calculated a directly adjusted Korean fatal injury rate using the industry specific number of workers in the United States as the standard population. This produced an overall rate estimate weighted by this standard population. ${ }^{13}$

\section{RESULTS}

For 1998-2001, 4830 unintentional occupational fatal injuries were observed in Korea while 18261 were recorded in the United States. The mean age of workers dying in an unintentional occupational fatal injury was 43.1 years in both countries. For years 1998-2001, the overall Korean occupational fatal injury rate was 13.8 deaths per 100000 workers while the rate in the United States was 3.6/100 000 (table 1). The directly standardized fatal injury rate in Korea when adjusted was 10.3 per 100000 workers. The rate in the United States when adjusted for Korean employment patterns was 5.5 per 100000 workers.

The percentages of workers in different industries in the two countries are displayed in table 1 . Construction and manufacturing made up a relatively higher fraction of the workforce in Korea $v$ the United States, $24 \% v 7 \%$ and $30 \% v$ $16 \%$, respectively. The United States had a significantly higher percentage of workers not employed in mining, construction, manufacturing, transportation or agriculture, forestry and fishing, $67 \%$ v $38 \%$.

The ordering of industries with respect to occupational fatal injury rates was the same in the two countries, with the highest observed rate in mining followed by agriculture/ forestry/fishing, construction, transportation/public utilities, manufacturing, and other industries (table 1). While $41 \%$ of unintentional occupational fatalities were in construction in Korea, $25 \%$ of such fatalities in the United States were in construction. A comparison of country specific rates within industry highlights that Korean rates are higher in each industry. The Korean rate was 1.5 times higher than that for the
United States in agriculture/forestry/fishing, two times higher in construction or transportation/public utilities, four times higher in manufacturing, and six times higher in mining.

The time trends across industry and country are shown in table 2. Rates in the United States remained relatively constant at approximately 3.6/100 000 over the study period, while Korean rates dropped approximately $13 \%$ over this four year period to 12.8/100 000 from 14.6/100 000 in 1998. All Korean industries exhibited a decline except mining and manufacturing. Agriculture/forestry/fishing dropped from 62.5/100 000 in 1998 to approximately 30/100 000 in 1999 and beyond. Industry specific rates in the United States were fairly stable with the exception of mining, which exhibited an approximate $50 \%$ increase over this four year period.

Annual time trend estimates are summarized in table 3. An annual decline across all industries of $5 \%$ per year and $<2 \%$ per year was estimated for Korea and the United States, respectively. Annual decreases of $6.7 \%$ and $3.2 \%$ in Korea and the United States, respectively, were estimated for construction. A significant decrease in transportation and a significant increase in manufacturing rates were observed in Korea, while a significant decrease in agriculture/forestry/fishing and significant increase in mining were observed in the United States.

The distribution of cause of death differed in Korea and the United States (table 4). The modal injury event in Korea was falls, $36 \%$ of deaths, while the modal event in the United States was motor vehicle related causes, $42 \%$ of the total in the United States. Motor vehicle related causes accounted for $19 \%$ of Korean deaths, and falls accounted for $15 \%$ of deaths in the United States. Contact with objects accounted for 27\% of Korean deaths and $21 \%$ of deaths in the United States. No other cause accounted for more than $10 \%$ of deaths in either country. Among the less frequent causes, the most notable difference in pattern between the two countries was air and water related incidents, which accounted for $6 \%$ of deaths in the United States but $<1 \%$ of Korean deaths.

\begin{tabular}{|c|c|c|c|c|c|c|c|}
\hline \multirow[b]{2}{*}{ Industry } & \multirow[b]{2}{*}{ Year } & \multicolumn{3}{|l|}{ Korea } & \multicolumn{3}{|c|}{ United States } \\
\hline & & Deaths & Employed & $\begin{array}{l}\text { Rate per } \\
100000\end{array}$ & Deaths & Employed & $\begin{array}{l}\text { Rate per } \\
100000\end{array}$ \\
\hline \multirow{4}{*}{$\begin{array}{l}\text { Agriculture, } \\
\text { forestry, } \\
\text { fishing }\end{array}$} & 1998 & 23 & 0.04 & 62.5 & 792 & 3.53 & 22.4 \\
\hline & 1999 & 25 & 0.09 & 27.6 & 742 & 3.43 & 21.6 \\
\hline & 2000 & 25 & 0.08 & 29.6 & 671 & 3.47 & 19.3 \\
\hline & 2001 & 36 & 0.11 & 31.9 & 688 & 3.30 & 20.9 \\
\hline \multirow[t]{4}{*}{ Mining } & 1998 & 33 & 0.02 & 138.6 & 142 & 0.62 & 22.8 \\
\hline & 1999 & 38 & 0.02 & 183.9 & 122 & 0.57 & 21.6 \\
\hline & 2000 & 23 & 0.02 & 113.5 & 153 & 0.52 & 29.3 \\
\hline & 2001 & 41 & 0.19 & 214.5 & 169 & 0.56 & 30.0 \\
\hline \multirow[t]{4}{*}{ Construction } & 1998 & 494 & 1.80 & 27.5 & 1136 & 8.54 & 13.3 \\
\hline & 1999 & 442 & 1.81 & 24.4 & 1168 & 9.00 & 13.0 \\
\hline & 2000 & 484 & 2.23 & 21.7 & 1114 & 9.44 & 11.8 \\
\hline & 2001 & 551 & 2.44 & 22.6 & 1182 & 9.58 & 12.3 \\
\hline \multirow[t]{4}{*}{ Manufacturing } & 1998 & 289 & 2.50 & 11.6 & 631 & 20.79 & 3.0 \\
\hline & 1999 & 315 & 2.34 & 13.5 & 671 & 20.09 & 3.3 \\
\hline & 2000 & 414 & 2.75 & 15.1 & 624 & 19.95 & 3.1 \\
\hline & 2001 & 390 & 2.92 & 13.3 & 547 & 18.99 & 2.9 \\
\hline \multirow[t]{4}{*}{ Transportation } & 1998 & 130 & 0.67 & 19.3 & 827 & 9.34 & 8.9 \\
\hline & 1999 & 127 & 0.65 & 19.6 & 918 & 9.56 & 9.6 \\
\hline & 2000 & 131 & 0.69 & 19.0 & 872 & 9.75 & 8.9 \\
\hline & 2001 & 104 & 0.71 & 14.7 & 835 & 9.76 & 8.6 \\
\hline Other & 1998 & 140 & 2.54 & 5.5 & 1072 & 83.27 & 1.3 \\
\hline \multirow{3}{*}{ businesses } & 1999 & 152 & 2.52 & 6.0 & 1044 & 85.15 & 1.2 \\
\hline & 2000 & 194 & 3.71 & 5.2 & 1085 & 86.31 & 1.3 \\
\hline & 2001 & 229 & 4.38 & 5.2 & 1056 & 86.96 & 1.2 \\
\hline Overall (all & 1998 & 1109 & 7.58 & 14.6 & 4600 & 126.09 & 3.6 \\
\hline \multirow{3}{*}{ industries) } & 1999 & 1099 & 7.44 & 14.8 & 4665 & 127.80 & 3.7 \\
\hline & 2000 & 1271 & 9.48 & 13.4 & 4519 & 129.45 & 3.5 \\
\hline & 2001 & 1351 & 10.58 & 12.8 & 4477 & 129.16 & 3.5 \\
\hline
\end{tabular}


A more detailed evaluation of injury causes within industries in the two countries is given in table 5. The top cause of death was the same for all industries except for agriculture/forestry/fishing where motor vehicle related causes accounted for over $40 \%$ of fatalities in the United States and only $15 \%$ of Korean fatalities (falls, the modal category for Korean fatalities, accounted for $26 \%$ of fatalities in this industry group). Not surprisingly, approximately $60 \%$ in transportation/public utilities were attributed to motor vehicle related causes. Contact with objects was the second most common injury cause for this industry. Contact with objects was the modal cause of death for mining $(65 \%$ in Korea and $40 \%$ in the United States); however, motor vehicle related causes were more frequent causes in the United States $(25 \%)$ compared with Korea $(4.5 \%)$. Causes of death in manufacturing were similar in the two countries with falls and motor vehicle related causes switching positions two and three in the top five cause list. The causes in construction were similar with contact with object, electric current, and fire/explosion accounting for a similar percentage of the injuries. Falls accounted for 55\% of construction deaths in Korea and $34 \%$ in the United States, while motor vehicle related causes accounted for $25 \%$ in the United States and $6 \%$ in Korea.

\section{DISCUSSION}

In the analyses described above, crude rates of occupational fatal injury were more than three times higher in Korea relative to the United States for 1998-2001. Directly adjusted rates accounting for employment differences were still 2.5 times higher in Korea. Thus, it appears that Korea-United States differences cannot be explained solely by differences in industry specific employment patterns. The general population unintentional fatal injury rate in 1999 was 45.7 per 100000 in $\mathrm{Korea}^{14}$ and 35.07 per 100000 in the United States. ${ }^{15}$ The difference in rates between the two countries is much larger than the difference in rates observed in the general population.

The ordering of industries with respect to risk of occupational fatal injury is the same in the two countries with mining, agriculture/forestry/fishing, and construction being the most dangerous. Overall, the risk is decreasing in these two countries, although at a faster rate in Korea.

Restricting attention to unintentional injuries, falls dominate the landscape in Korea while motor vehicle related causes dominate in the United States. The nature of construction in Korea, being frequently high building construction, may help explain this cause. The availability of mass transit in Korea coupled with the lack of this in the United
Table 4 Comparison of events or exposure for unintentional fatal occupational injuries between Korea and the United States by number of events and percentage distribution; values are number (\%)

\begin{tabular}{lll}
\hline Injury event or exposure & Korea & United States \\
\hline Falls & $1720(35.7)$ & $2842(15.5)$ \\
Contact with objects & $1307(27.2)$ & $3792(20.7)$ \\
Motor vehicle collision & $931(19.4)$ & $7692(41.9)$ \\
Electrocutions & $391(8.1)$ & $1101(6.0)$ \\
Explosions/fires & $230(4.8)$ & $686(3.7)$ \\
Drowning/suffocation & $117(2.4)$ & $302(1.6)$ \\
Poisonings & $49(1.0)$ & $385(2.1)$ \\
Air and water incidents & $40(0.8)$ & $1081(5.9)$ \\
Nature/environment & $27(0.6)$ & $146(0.8)$ \\
Other & $18(0.4)$ & $327(1.8)$ \\
Total & $4830(100)$ & $18354(100)$ \\
\hline
\end{tabular}

States may account for the higher importance of motor vehicle related causes in the United States. Another potentially important explanatory factor for this difference is the age when driver's licenses are obtained. In the United States, 16 year olds are eligible while Korea does not license drivers until they are 19.

Differences could be the result of a variety of factors including the disparity in the risk from injuries between the countries and discrepancies in data collecting systems. Bias in the comparison of occupational fatalities can arise from two main sources of mismatch between countries. First, the populations covered by fatality and employment sources can differ within and between countries. Second, classification systems for injury and industry groups could differ.

Both countries' fatality and employment data were internally consistent. Korean data on employment was based upon enrollment in a workers' compensation system while the United States employment estimate was based on a survey. Korean occupational fatal injury counts were based on compensation claims whereas counts in the United States were based on a multiple source surveillance system, CFOI. Although CFOI's requirement of multiple sources to confirm an occupational fatality may restrict the number of deaths captured, it also expands the coverage beyond that observed in surveillance systems that use only a single source. Companies with fewer than five employees were not included in Korea's systems before June 2000. At the end of 2001, KLWC included only $67 \%$ of small sized companies and only recently began including self employed workers with more than one employee. Data from the United States included both small sized companies and self employed workers. Research has

Table 3 Estimated fatal occupational injury rate per 100000 worker years in 1998 and annual rate of change for the years 1998-2001 in Korea and the United States (US)

\begin{tabular}{|c|c|c|c|c|}
\hline Group & Country & $\begin{array}{l}1998 \text { Rate } \\
\text { per } 100000\end{array}$ & Annual change (\%) & $\begin{array}{l}95 \% \text { Confidence } \\
\text { interval change (\%) }\end{array}$ \\
\hline \multirow[t]{2}{*}{ Overall } & Korea & 14.95 & -4.95 & $(-7.31$ to -2.54$)$ \\
\hline & US & 3.67 & -1.96 & $(-3.22$ to -0.68$)$ \\
\hline \multirow{4}{*}{$\begin{array}{l}\text { Agricultural, } \\
\text { forestry, fishing } \\
\text { Mining }\end{array}$} & Korea & 43.84 & -14.06 & $(-28.20$ to 2.86$)$ \\
\hline & US & 22.11 & -3.29 & $(-6.41$ to -0.08$)$ \\
\hline & Korea & 140.10 & 9.90 & $(-5.38$ to 27.65$)$ \\
\hline & US & 21.78 & 11.75 & (4.06 to 20.01 ) \\
\hline \multirow[t]{2}{*}{ Construction } & Korea & 26.60 & -6.70 & $(-10.28$ to -2.97$)$ \\
\hline & US & 13.21 & -3.15 & $(-5.62$ to -0.61$)$ \\
\hline \multirow[t]{2}{*}{ Manufacturing } & Korea & 12.38 & 5.03 & $(0.27$ to 10.03$)$ \\
\hline & US & 3.19 & -2.04 & $(-5.43$ to 1.48$)$ \\
\hline \multirow[t]{2}{*}{ Transportation } & Korea & 20.34 & -7.75 & $(-14.73$ to -0.21$)$ \\
\hline & US & 9.23 & -1.78 & $(-4.69$ to 1.21$)$ \\
\hline \multirow[t]{2}{*}{ Other business } & Korea & 5.71 & -2.89 & $(-9.04$ to 3.68$)$ \\
\hline & US & 1.27 & -1.49 & $(-4.10$ to 1.19$)$ \\
\hline
\end{tabular}




\begin{tabular}{|c|c|c|c|c|}
\hline \multirow[b]{2}{*}{ Industry } & \multicolumn{2}{|l|}{ Korea } & \multicolumn{2}{|l|}{ United States } \\
\hline & Injury & Deaths (\%) & Injury & Deaths (\%) \\
\hline \multirow{8}{*}{$\begin{array}{l}\text { Agriculture, } \\
\text { forestry, } \\
\text { fishing }\end{array}$} & Falls & $27(25.5)$ & Motor vehicle collision & $1287(44.5)$ \\
\hline & Contact with object & $24(22.0)$ & Contact with object & $723(25.0)$ \\
\hline & Air/water incident & $20(18.9)$ & Air/water incident & $291(10.1)$ \\
\hline & Drown/suffocate & 18 (16.0) & Falls & $228(7.9)$ \\
\hline & Motor vehicle collision & $16(15.1)$ & Electric current & $141(4.9)$ \\
\hline & Total & $109(100)$ & Total & $2893(100)$ \\
\hline & Contact with object & $87(64.9)$ & Contact with object & $232(39.6)$ \\
\hline & Falls & $24(17.9)$ & Motor vehicle collision & $145(24.7)$ \\
\hline \multirow[t]{6}{*}{ Mining } & Fire/explosion & $9(6.7)$ & Fire/explosion & $76(13.0)$ \\
\hline & Motor vehicle collision & $6(4.5)$ & Falls & $54(9.2)$ \\
\hline & Electric current & $3(2.2)$ & Electric current & $19(3.2)$ \\
\hline & Total & $135(100)$ & Total & $586(100)$ \\
\hline & Falls & $1082(55.0)$ & Falls & 1558 (33.9) \\
\hline & Contact with object & $433(22.0)$ & Motor vehicle collision & $1166(25.3)$ \\
\hline \multirow[t]{6}{*}{ Construction } & Electric current & $228(11.6)$ & Contact with object & $919(20.0)$ \\
\hline & Motor vehicle collision & $110(5.6)$ & Electric current & $592(12.9)$ \\
\hline & Fire/explosion & $54(2.7)$ & Fire/explosion & $126(2.7)$ \\
\hline & Total & $1971(100)$ & Total & $4600(100)$ \\
\hline & Contact with object & $567(40.5)$ & Contact with object & 975 (39.4) \\
\hline & Falls & $327(23.3)$ & Motor vehicle collision & $697(28.2)$ \\
\hline \multirow[t]{6}{*}{ Manufacturing } & Motor vehicle collision & $213(15.2)$ & Falls & $241(9.7)$ \\
\hline & Fire/explosion & $123(8.8)$ & Fire/explosions & $193(7.8)$ \\
\hline & Electric current & $108(7.7)$ & Electric current & $124(5.0)$ \\
\hline & Total & $1408(100)$ & Total & $2473(100)$ \\
\hline & Motor vehicle incident & $298(60.6)$ & Motor vehicle incident & $2256(65.4)$ \\
\hline & Contact with object & $88(17.9)$ & Air/water incident & $342(9.9)$ \\
\hline \multirow{5}{*}{$\begin{array}{l}\text { Transportation, } \\
\text { public utilities }\end{array}$} & Falls & $74(15.0)$ & Contact with object & 339 (9.8) \\
\hline & Electric current & $10(2.1)$ & Falls & $152(4.4)$ \\
\hline & Air/water incident & $7(1.4)$ & Electric current & $88(2.5)$ \\
\hline & Total & $492(100)$ & Total & $3452(100)$ \\
\hline & Motor vehicle incident & $288(40.3)$ & Motor vehicle incident & 2097 (49.3) \\
\hline \multirow{5}{*}{$\begin{array}{l}\text { Other } \\
\text { businesses }\end{array}$} & & $186(26.0)$ & Contact with object & $593(13.9)$ \\
\hline & Contact with object & $108(15.1)$ & Falls & $590(13.9)$ \\
\hline & Electric current & $40(5.6)$ & Air/water incident & $308(7.2)$ \\
\hline & Fire/explosion & $37(5.2)$ & Fire/explosion & $188(4.4)$ \\
\hline & Total & $715(100)$ & Total & $4257(100)$ \\
\hline
\end{tabular}

shown that workers in small sized companies or who are self employed experience higher rates. ${ }^{16}$ We conjecture that the exclusion of small size companies and self employed workers in Korea indicates that the risks presented here underestimate the true fatality rates in Korea, and that the differences between countries are larger than those stated here.

Classification of industry and injury groups could also present differences. Employment data were available only at the major division level, so it was not possible to separate specific industries from larger industry groups. As a check of the validity of matching based on industry division, individual industries were matched at the two digit standard industrial code level. At this level, the most notable differences were that logging industries were included in agriculture, forestry, and fishing in Korea, and as manufacturing in the United States, and sanitation services were listed as services in Korea, and under transportation, communications, and public utilities in the United States. Since these were the largest observed differences, and this represented relatively small groups, no adjustments were made. This preserved the internal validity of rates within countries.

Injuries were classified into 10 large groups of injury types. As mentioned earlier, intentional injuries in the United States were excluded to maintain compatibility with Korean data, where these events are rare. If these fatalities were included in the comparisons, fatality rates in the United States would be increased by nearly $20 \%$. In matching injury causes, not all causes were matched in the two countries. Nineteen Korean fatalities that did not have equivalents in the United States were removed. If these were included, this would result in an increase in the Korean fatality rate slightly, but increase in the discrepancy between countries.

Though relatively comparable industry and injury classification systems exist between these countries, many other factors affect the rates. Injury risk may depend on a host of factors including worker demographic factors such as age and education level, and workplace factors (for example, mean job duration and shift work). Several potential explanations are given here for the differences observed between the countries. The mix of industries within countries and differences in work organization, processes, products, and technologies are also possible explanations. Since the difference in fatality rates was still substantial after adjusting for differences in the mix of industries, factors within industries (for example, differences in production processes) are likely to be important.

Using the number of workers employed as the denominator may cause differences in risk estimates as well. Ruser described differences in rates that result from using either the number of hours or number of employees in rate calculations. ${ }^{17}$ Since the total weekly working hours of Korean workers are much higher than those in the United States, the use of number employed, as performed here, may accentuate estimated rate differences between the countries. ${ }^{16}$

The lack of detailed information such as number of workers by sex, age, and kinds of industry restricts the analyses. Even though we were unable to conduct analyses adjusting for these factors, our analyses provide a prediction of the overall trend in Korea. If employment in industry in Korea shifts from manufacturing to service sector jobs, as has 


\section{Key points}

- Korean unintentional occupational fatal injury rates are at least twice as large as corresponding American rates.

- Workers in mining, agriculture/forestry/fishing, and construction experience the highest rates in both Korea and the United States.

- Some evidence of decreasing time trends is available in both countries.

- Falls are the main cause in Korea while motor vehicle related causes are the main cause in the United States.

- International comparisons of injury rates require reconciliation of coding differences for industry groupings, causes of death, etc.

been observed in the United States, then these injuries in Korea may increase among workers in the service sector and among age groups often employed to greater degrees in this industry-for example, younger and older employees. Of course, overall mortality will be decreased according to the change of industry structure from primary to tertiary. However, rates in Korea are still higher than those in the United States. Korea can learn from experiences in the United States to prevent injuries in the current mix of industries and to set up strategies for preventing injuries in the future as the mix of Korean employment patterns change.

International efforts to harmonize injury data for comparing injury experience across countries are ongoing. The International Collaborative Effort (ICE) on Injury Statistics addressed many of the coding issues we described above. ${ }^{18}$ Fingerhut et al published comparisons of injury mortality rates in the 11 countries who participate in the ICE which also highlighted high frequencies of fall related and motor vehicle related causes. ${ }^{19}$ Country specific differences in death certification and coding practices are credited with differences observed in higher fatal injury death rates for older New Zealanders compared with older American citizens. ${ }^{20}$ Williamson et al suggested that a narrative analysis of text describing injury mechanisms might help reconcile some coding differences in an analysis of fatal injuries in Australia, New Zealand, and the United States. ${ }^{21}$ Driscoll et al also examined the attribution of work relatedness to fatal injuries in these countries. ${ }^{22}$ Based on scenarios tested in these studies, they concluded that difference existed in the attribution of work relatedness. Unlike these studies, we faced the challenge of reconciling coding differences between two countries with different languages.

The International Labour Organization defines an occupational injury as "any personal injury, disease or death resulting from an occupational accident" with coverage of workers including "... all workers regardless of their status in employment (for example, employee, employer and ownaccount worker). Coverage should include child workers, informal sector workers and homeworkers, where they exist". ${ }^{23}$ This source also defined a fatal occupational injury as "an occupational injury leading to death within one year of the day of the occupational accident". Such coverage and breadth is difficult to achieve in current transnational comparisons although it does provide a target for current and future efforts.

\section{ACKNOWLEDGEMENTS}

This project was initiated and completed while the first author was visiting NIOSH as part of the KOSHA visiting scientist program. The authors would like to thank Dr Leslie Stayner for discussions related to the conceptualization of this project. In addition, the authors would like to thank Drs D Loomis, K Sieber, N Stout, B Pless, and anonymous reviewers for insightful comments and suggestions for improving this manuscript.

\section{Authors' affiliations}

Y-S Ahn, Korea Occupational Safety and Health Agency, Incheon, Korea

J F Bena, Risk Evaluation Branch, National Institute for Occupational Safety and Health, Cincinnati, Ohio, USA

A. J Bailer, Risk Evaluation Branch, National Institute for Occupational Safety and Health, Cincinnati, Ohio and Department of Mathematics and Statistics and the Scripps Gerontology Center, Miami University, Oxford, Ohio, USA

\section{APPENDIX}

Table 1 Comparison of occupational injury surveillance system between Korea and the United States

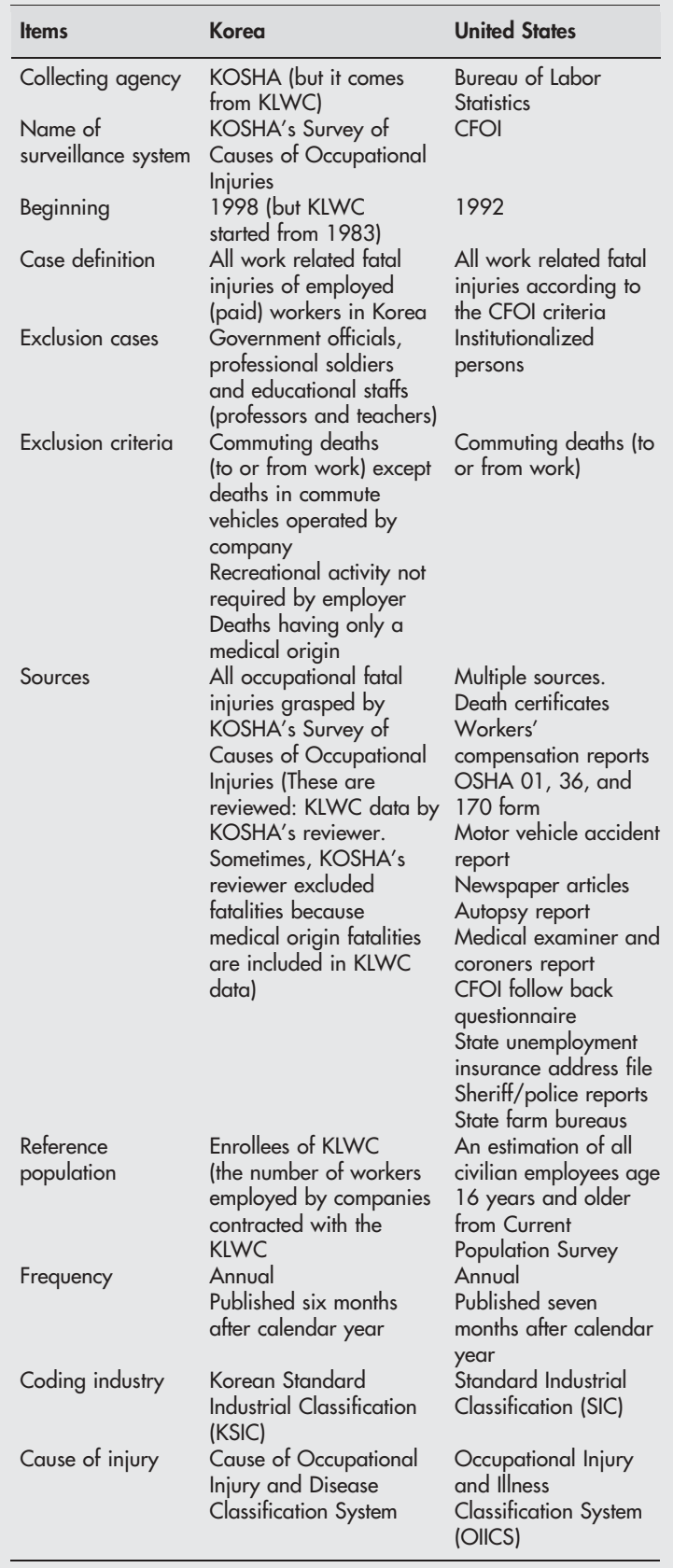


Table 2 Classification of industry groups and industry codes from the Standard Industrial Classification (SIC) system in Korea and the United States

\begin{tabular}{lll}
\hline Industry division name & $\begin{array}{l}\text { Korean SIC } \\
\text { division codes }\end{array}$ & $\begin{array}{l}\text { United States SIC } \\
\text { division codes }\end{array}$ \\
\hline Agriculture, forestry, fishing & G, H, I & A \\
Mining & B & B \\
Construction & E & C \\
Manufacturing & C & D \\
Transportation/communication/ & D, F & E \\
utilities & A, J & F, G, H, I, J \\
Other industries & & \\
\hline
\end{tabular}

Table 3 Classification of fatal injuries into injury groups based on the Occupational Injury and Illness Classification System (OIICS) and Causes of Occupational Injury and Disease Classification System (COIDSS)

\begin{tabular}{lll}
\hline Event group name & $\begin{array}{l}\text { United States OIICS } \\
\text { codes }\end{array}$ & $\begin{array}{l}\text { Korean COIDSS } \\
\text { codes }\end{array}$ \\
\hline Drowning/suffocation & $381-384$ & 15,42 \\
Electrocutions & $310-319$ & 08 \\
Explosions & $520-529$ & 09 \\
Fires & $510-519$ & 11 \\
Falls & $100-190$ & 01,02 \\
Contact with objects & $000-090$ & $03,04,06,07$ \\
Motor vehicle collision & $400-433$ & 50,51 \\
Nature/environmental & $320-329$ & 13 \\
Poisonings & $341-349$ & 41 \\
Air/water incidents & $450-469$ & 52 \\
\hline
\end{tabular}

\section{REFERENCES}

1 Takala J. Global estimates of fatal occupational accidents. Epidemiology 1999;10:640-6.

2 Korea Ministry of Labor. 2000 Statistics of industrial accidents. Seoul, Korea: Korea Ministry of Labor, 2001.
3 Korea Industrial Safety Corporation. The history book for 10 years: changes of occupational safety and health with the times. Korea Industrial Safety Corporation, 1997.

4 Austin C. An evaluation of the Census of Fatal Occupational Injuries as a system for surveillance. Comp Work 1995;May:51-4.

5 US Department of Labor Bureau of Labor Statistics. Census of Fatal Occupational Injuries profiles data 1992-2001. Washington, DC: US Government, 2003.

6 US Bureau of the Census. The current population survey: design and methodology. Technical Paper 40. Washington, DC: US Government, 1978.

7 Office of Management and Budget. Standard industrial classification manual. Washington, DC: Office of Management and Budget, 1987.

8 Korea National Statistical Office. Korean standard industrial classification system. Seoul, Korea: Korea National Statistical Office, 2000.

9 US Department of Labor Bureau of Labor Statistics. Occupational injury and illness classification manual. Washington, DC: US Government, 1992.

10 Korea Occupational Safety and Health Agency. Causes of occupational injury and disease classification system. Seoul, Korea: Korea Occupational Safery and Health Agency, 1998.

11 McCullagh P, Nelder J. Generalized linear models. 2nd Ed. New York: Chapman \& Hall, 1989.

12 SAS Institute. SAS/STAT user's guide. Version 8. 4th Ed, volume 1. Cary, NC: SAS Publishing, 2000.

13 Lee ET. Statistical methods for survival data analysis. Belmont, CA: Lifetime Learning Publications, 1980

14 Korea National Statistical Office. 2001 Statistics of cause of death. Seoul, Korea: Korea National Statistical Office, 2002.

15 National Center for Injury Prevention and Control. Web-based injury statistics query and reporting system. Available at: http://www.cdc.gov/ ncipc/wisqars/ (accessed 20 April 2004).

16 Korea Ministry of Labor. Statistics of labor in foreign countries. Seoul, Korea: Korea Ministry of Labor, 2002.

17 Ruser JW. Denominator choice in the calculation of workplace fatality rates. Am J Ind Med 1998;33:151-6.

18 National Center for Health Statistics. ICE projects-occupational injury. Available at: http://www.cdc.gov/nchs/about/otheract/ice/occup.htm (accessed 20 April 2004)

19 Fingerhut LA, Cox CS, Warner M, et al. International comparative analysis of injury mortality: findings from the ICE on injury statistics. Advance data from vital and health statistics; No 303. Hyattsville, MD: National Center for Health Statistics, 1998.

20 Langlois JA, Smith GS, Baker SP, et al. International comparisons of injury mortality in the elderly: issues and differences between New Zealand and the United States. Int J Epidemiol 1995;24:136-43.

21 Williamson A, Feyer A-M, Stout N, et al. Use of narrative analysis for comparisons of the causes of fatal accidents in three countries: New Zealand, Australia, and the United States. Inj Prev 2001;7:i15-20.

22 Driscoll T, Feyer A-M, Stout $N$, et al. Assessing the classification of workrelatedness of fatal incidents: a comparison between Australia, New Zealand, and the United States. Injury Control and Safety Promotion 2002;7:32-9.

23 International Labour Organization. Resolution concerning statistics of occupational injuries resulting from occupational accidents), adopted by the Sixteenth International Conference of Labour Statisticians (October 1998). Available at: http://www.ilo.org/public/english/bureau/stat/res/accinj.htm (accessed 20 April 2004). 